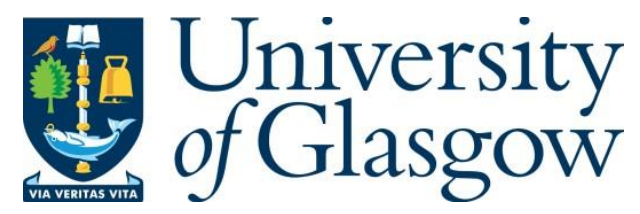

Armstrong, J. D., Bean, C. W. and Wells, A. (2018) The Scottish invasion of pink salmon in 2017. Journal of Fish Biology, 93(1), pp. 8-11.

There may be differences between this version and the published version. You are advised to consult the publisher's version if you wish to cite from it.

This is the peer reviewed version of the following article Armstrong, J. D., Bean, C. W. and Wells, A. (2018) The Scottish invasion of pink salmon in 2017. Journal of Fish Biology, 93(1), pp. 8-11, which has been published in final form at http://dx.doi.org/10.1111/jfb.13680. This article may be used for non-commercial purposes in accordance with Wiley Terms and Conditions for Self-Archiving.

http://eprints.gla.ac.uk/187820/

Deposited on: 13 June 2019

Enlighten - Research publications by members of the University of Glasgow http://eprints.gla.ac.uk 


\title{
OPINIONS
}

\section{The Scottish invasion of pink salmon in 2017}

\author{
1John D. Armstrong, ${ }^{2}$ Colin W. Bean and ${ }^{3}$ Alan Wells \\ ${ }^{1}$ Freshwater Fisheries Laboratory, Marine Scotland Science, Faskally, Pitlochry, Perthshire, \\ U.K. \\ ${ }^{2}$ Scottish Natural Heritage, Caspian House, Mariner Court, Clydebank Business Park, \\ Clydebank, U.K. \\ ${ }^{3}$ Fisheries Management Scotland, 11 Rutland Square, Edinburgh, U.K.
}

A brief background on Oncorhynchus gorbuscha (Walbaum, 1792).

Pink salmon (Oncorhynchus gorbuscha) (see reviews by Heard, 1991 and Quinn, 2006) is the smallest of the migratory Pacific salmon.. As natives of the Pacific Ocean, they spawns in fresh water at latitudes between about 40 and $70^{\circ} \mathrm{N}$ in countries bordering both sides of the Pacific Ocean. They generally have a two-year life cycle and populations of "odd" and "even" year fish can coexist in the same stretch of river, typically the lower river reaches, without significant gene exchange. Spawning time varies from August to November across the native home range. Fish emerge mostly between April and June depending on the latitude, already silvery in colour and ready for seawater (Sackville et al., 2012).

Remarkably, most populations migrate out to sea immediately and with a diminuitive size of $\sim 30 \mathrm{~mm}$ and a mass of just $0.2 \mathrm{~g}$ (Peacock et al., 2014). Pink salmon (likely 500) were accidentally introduced into Lake Superior of Canada and the USA in the 1950's and subsequently spread throughout the Great Lakes, where they are avidly fished today as a recreational species.

This opinion piece concerns the straying of pink salmon into Scottish rivers after they were stocked into and subsequently naturalised in certain Russian rivers in the North Atlantic. They subsequently spread southward and invaded Norwegian rivers (Mo et al., 2018). They have also "jumped" across the North Atlantic Sea, which raises conservation concerns for the UK.

The historic warning signs and the explosive invasion

Pink salmon were occasionally reported as being been caught in Scotland over 50 years ago (Pyefinch, 1962; Williamson, 1974; Maitland, 2007): 1 fish in 1960, 1965, 2007, 2009, 2012 and 2015; 2 fish in 1967 and 2011; and 5 fish in 1973). Although most records are from odd year populations, individuals have also been captured in even years. Against this sporadic appearance, the 2017 reports represent an unusual and explosive invasion of pink salmon to Scotland. A total of 139 pink salmon were recorded across a broad range of rivers (Fig. 1): 75 captured by rod-and-line angling, 24 in commercial nets, 26 from targeted netting; 8 observed alive and 6 found dead. This reported sample undoubtedly underestimates the overall number of pink salmon entering Scottish rivers .

An invasion of spawning adults or establishment of feral populations?

To establish a feral population of pink salmon in Scottish rivers, the fish must first successfully spawn. Indeed, pink salmon eggs were recovered from excavated nests on the Dee (Aberdeenshire), Spey and Ness Rivers. Spawning was observed between 11-14 August in the rivers Spey, Ness and Dee and a second period of spawning was observed on the Dee on 2 September. This first spawning period was similar in timing to that recorded in 
Norway (Mo et al., 2018). The furthest upstream observations of pink salmon were in the River Spey $81 \mathrm{~km}$ from head-of-tide.

\section{What are scientists investigating?}

Opportunistic studies have commenced and are currently in progress for this unexpected pink salmon invasion. Genetic samples are being compared with Russian and Pacific pink salmon populations to identify the origin of the Scottish invaders. Also, a sample of eggs spawned on 12 August 2017 in the River Dee was collected and subsequently reared under controlled laboratory conditions across a range of temperatures up to $22^{\circ} \mathrm{C}$ to assess the viability of pink salmon outside their normal thermal range. Combining these observations with already published egg and alevin development rates (Quinn, 2005), and comparison with typical temperatures in Scottish rivers, indicates that emergence and emigration of fry occurred during late autumn/early winter (unpublished). These predictions correspond with observations of the development of pink salmon at ambient temperature in the laboratory and in the rivers Spey (B. Shaw, pers. comm.) and Ness (C. Conroy, pers. comm.). Evidently, Scottish rivers are sufficiently warm that any surviving fry would likely have entered the sea at the onset of winter during the period of lowest productivity. Pink salmon in their natural range, just like native Scottish migratory salmonids, would emigrate to sea at a time that matches the spring and early summer bloom in production of food items when water temperatures rise. Consequently, scientists are predicting that offspring of the pink salmon that invaded Scotland would likely suffer very high marine mortality as a consequence of this mismatch in emigration time with food availability in the sea. But, there is no confirmatory evidence yet. Ultimately, and because of the 2-year life cycle, Scottish scientists must wait until 2019 for any pink salmon returns to Scottish rivers from these eggs. In meantime, information on the survival and growth rate of pink salmon will be combined with modelled temperature in Scotland to predict risk of these invaders founding selfsustaining populations across ranges in a range of Scottish rivers with a variety of spawning dates and realistic variations in river temperatures.

\section{Potential indirect effects of the pink salmon invasion on our native fauna}

The good news is that Atlantic salmon Salmo salar Linnaeus, 1758 and brown trout Salmo trutta Linnaeus, 1758 in Scotland spawn in autumn and winter and so competition from pink salmon for spawning areas is temporally mismatched. However, spawning pink salmon may have disturbed nests of sea lamprey Petromyzon marinus (Linnaeus, 1758), which are a protected species in Europe. Sea lamprey spawning starts in late May-June, when river temperatures reach $15^{\circ} \mathrm{C}$ (Beamish, 1980), and peaks when water temperature reaches 17$19^{\circ} \mathrm{C}$ (Hanson et al., 2016). Their redds are constructed in areas similar to those used by spawning pink salmon. While lamprey eggs have a relatively short incubation period, they subsequently may remain in the gravel for 10-13 days before moving downstream as larvae to suitable juvenile holding habitat (Piavis, 1972). If pink salmon were to create redds or otherwise disturb gravels during the period when sea lamprey eggs were incubating within spawning nests, it is possible that eggs may be exposed, displaced or lost due to damage or predation. Observations made during 2017 suggest that interactions between these two species may be limited if the earliest spawning commences in August, but this may not be the case in every year and fish were seen to exhibit redd-making behaviour well in advance of actual spawning. Relatively little is known about the actual status of sea lamprey in individual rivers, but it is considered to be rare at both a UK and wider European level. The disturbance of sea lamprey nests, and the potential loss of recruits, could be considered to be damaging to affected populations.

Given that spawning of pink salmon might not impact the spawning of native Scottish salmonids, the next concern is competition from the emergent fry. As noted above, emergent pink salmon fry are tiny and usually migrate directly to sea. Therefore, pink salmon 
are unlikely to displace or damage young-of-the-year juveniles of native Scottish salmonids since these are much larger by autumn. Pink salmon are very gregarious at sea and could exert strong local competition for food. However, fry do not usually feed extensively in fresh water (but see Mo et al., 2018)and extensive competition with native fish for food is not expected. In fact, the diminutive size of pink salmon makes them highly vulnerable to predation in rivers following emergence and hence they are more likely to be a valuable food source for native fish and other biota. The period where there is likely to be competition with native fishes is when adult pink salmon are creating and defending nests. Adult pink salmon are highly aggressive at this time and may damage, kill or exclude fish from areas of river, or interfere with migration. Such interactions may have affected freshwater pearl mussels Margaritifera margaritifera (Linnaeus, 1758) at the stage where they are attached to gills of Atlantic salmon and brown trout.

Decaying carcasses of adult pink salmon, which naturally die after spawning in the river, would actually provide localised enrichment from marine derived nutrients. The effects of this addition of organic material could be positive in nutrient depleted rivers, but negative in rivers already heavily impacted by anthropogenic nutrient enrichment. However, there was no quantitative evidence from Scotland of the extent of any such potential interactions. The impact that increased nutrient concentrations may have on freshwater pearl mussels is similarly unclear.

Management options for the pink salmon invasion

Excavation or disruption of pink salmon nests, either to destroy eggs or remove them for experimentation were made in some rivers. However, conclusions were that the approach was too resource intensive and incurred substantial human health and safety risks to operators to be a viable option for widespread application as a control measure. Also, netting of pink salmon would risk damage to Atlantic salmon, a protected species and a high economic value target species for fisheries. Pink salmon could be vulnerable to targeted angling. Experience in Norway indicates that they may be selectively removed by scuba divers using spear guns (Mo et al., 2018). These methods may be useful in future management to remove adult pink salmon, but efficiency is likely variable and dependent on river location and local conditions. For example, targeting pink salmon would be difficult in coloured water in large rivers. Thus, the costs and benefits of further developing such management approaches will be influenced by future experience, as well as the extent and regularity of invasions of pink salmon and scientific assessments of the potential for colonisation and negative impacts on native fauna. Assessments of the extent of future invasions would be facilitated by early monitoring through active search (e.g., application of eDNA) and the establishment of a more defined reporting structure (from anglers and others).

\section{Future outlook}

It is unclear why so many more pink salmon invaded in Scotland in 2017 compared with previous years. Likely, the fish originated from the Russian or Northern Norway populations due to unusually high freshwater production, a high marine survival, or perhaps a change in the distribution of adults at sea. Perhaps of greatest concern is that, if progressive change in climate is a root cause, then invasions of pink salmon to Scottish waters will likely continue. But at this stage the magnitude and frequency of such occurrence cannot be predicted. Furthermore, there is no evidence yet of substantial damage to native fauna from the 2017 invasion.

Current thinking, using existing understanding of the biology of pink salmon is that that selfsustaining local populations of pink salmon in Scottish rivers is unlikely. However, we have not eliminated the possibility of earlier colonisation due to so few reported observations of 
pink salmon prior to the 2017 invasion. On this basis the potential for substantial damage seems to be low, although a formal process is underway to assess risks drawing on a full assessment of available information from across the United Kingdom. The greatest concern is that if future invading pink salmon spawn later in the year then the current assessment would require a drastic re-evaluation, since this might result in a spring emigration of pink salmon, which would increase the chances of subsequent survival at sea and increase likelihood of populations becoming established. While survival of fry emigrating to sea in autumn being higher than anticipated is an additional concern, this seems unlikely because the situation in Scotland seems similar to that in central Californian rivers, where pink salmon can stray from more northern populations but do not sustain discrete local populations. Moreover, most efforts to deliberately transplant pink salmon have failed, with the notable exception of the Great Lakes. In contrast, introductions of pink salmon to western Russia were very successful and if that is the provenance of the Scottish fish then they may be genetically selected to be different from original populations and successful invaders.

At this stage, a rapid response to the 2017 invasion has allowed Scottish scientists and managers to collect key information on the biology of these invading pink salmon to assess the situation. The experience has primed the fisheries management and scientific communities to be prepared and more watchful for significant future invasions and to have coordinated responsive action plans in place should this occur. These response actions should preferably be standardised in Scotland and throughout those Scandinavian and European countries that are affected.

\section{Acknowledgements}

We are grateful to many colleagues and organisations for providing and preparing information and for discussions about the pink salmon invasion, including Mark Bilsby, Brian Davidson, Chris Conroy, , Simon Dryden, Sean Dugan, Ross Gardiner, Lorraine Hawkins, Brian Shaw, and the Ness, Spey and Dee Fisheries Boards. However, the opinions expressed here are those of the authors. Particular thanks to Sean Dugan for producing the map.

Beamish, F.W.H. (1980). Biology of the North American anadromous sea lamprey, Petromyzon marinus, Canadian Journal of Fisheries and Aquatic Sciences 37,1924-1943.

Hansen, M.J., Madenjian, C.P., Slade, J.W., Steeves, T.B., Almeida, P.R. \& Quintella, B.R. (2016). Population ecology of the sea lamprey (Petromyzon marinus) as an invasive species in the Laurentian Great Lakes and an imperiled species in Europe. Reviews in Fish Biology and Fisheries 26, 509-535.

Hardisty, M.W. (1986). Petromyzon marinus Linnaeus, 1758. In: J. Holčík (ed,) The Freshwater Fishes of Europe, vol 1, part 1, Petromyzontiformes. AULA-Verlag, Wiesbaden, pp 96-116.

Heard, W.R. Life history of pink salmon (Oncorhynchus gorbuscha), In C. Groot \& L. Margolis (eds.) Pink Salmon Life Histories. pp.119-230. UBC Press, Vancouver,

Maitland, P.S. 2007. Scotland's Freshwater Fish: Ecology, Conservation \& Folklore. Trafford Publishing, Oxford. 436pp. 
Peacock, S.J., Connors, B.M., Krkošek, M., Irvine, J.R. \& Lewis, M.A. (2014). Can reduced predation offset negative effects of sea louse parasites on chum salmon? Proceedings of the Royal Society B: Biological Sciences. 2014;281(1776):20132913.

Piavis, G.W. 1972. Embryology. In: M.W. Hardisty \& I.C. Potter, (eds.) The Biology of Lampreys. Vol. 1. Academic Press, New York, pp. 361-400.

Pyefinch K.A. (1962). Capture of pink salmon on the Scottish coast. Ann Biol 17(1960):238

Quinn, T.P. (2005). The Behavior and Ecology of Pacific Salmon \& Trout. University of Washington Press, Seattle.

Sackville, M., JWilson, J.M., Farrell, A.P. \& C.J. Brauner. 2012. Water trumps ion balance for early marine survival of juvenile pink salmon ( $O$. gorbuscha). Journal of Comparative Physiology, B 182, 781-792.

Willamson R.B. (1974). Further captures of Pacific salmon in Scottish waters. Scottish Fisheries Bulletin 41, 28-30. 
Fig. 1. Map showing the distribution of pink salmon records throughout Scotland in relation to fishery districts.

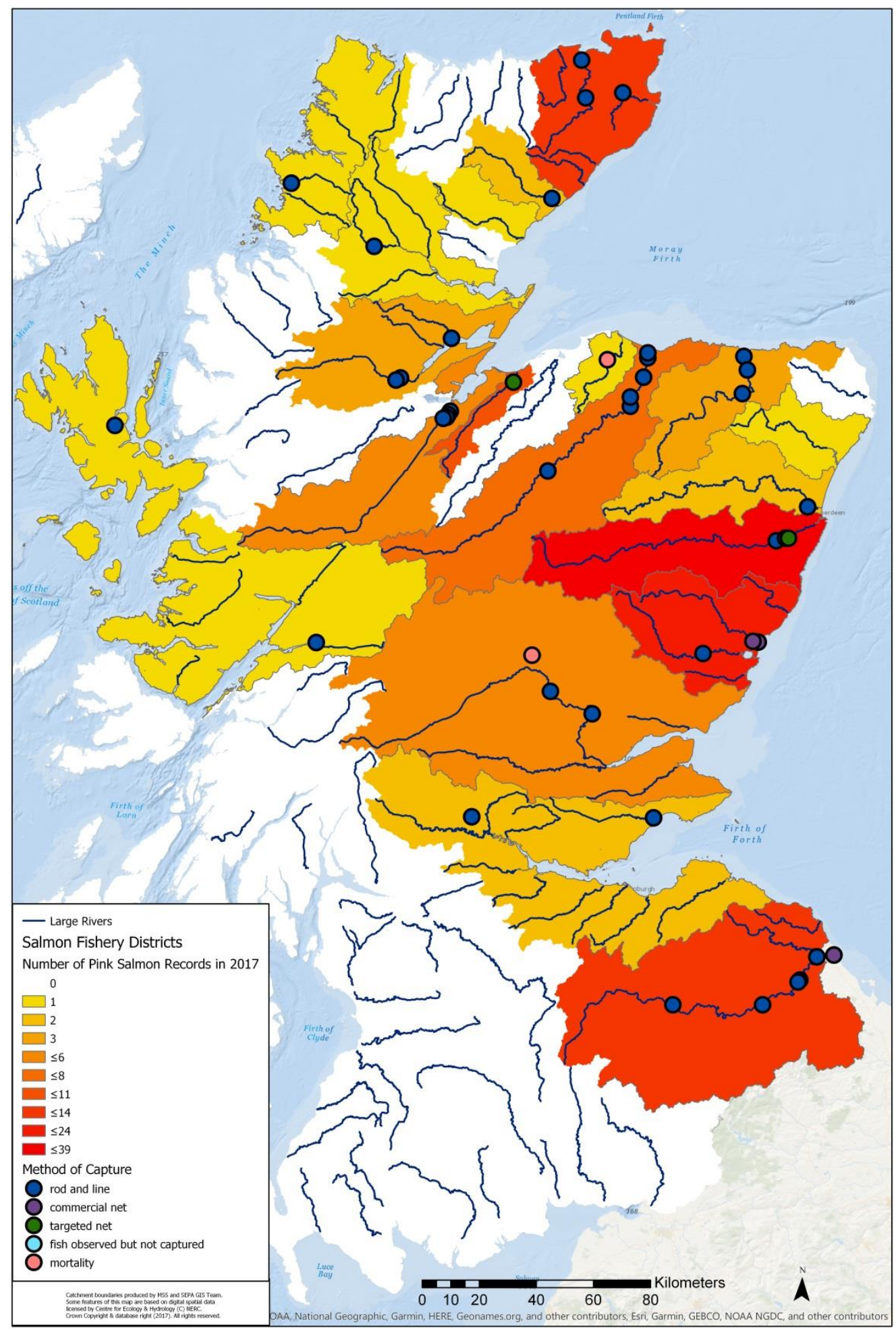

